\title{
Proliferative ductular reactions correlate with hepatic progenitor cell and predict recurrence in HCC patients after curative resection
}

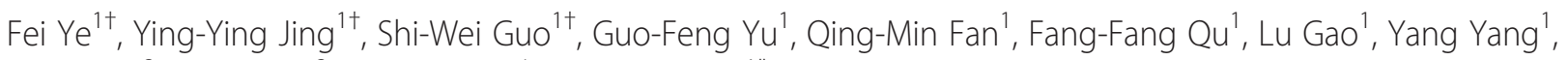
Dong $\mathrm{Wu}^{2}$, Yan Meng ${ }^{3}$, Feng-Hai $\mathrm{Yu}^{4}$ and Li-Xin Wei ${ }^{i^{*}}$

\begin{abstract}
Background: Ductular reactions (DRs) are well documented in many acute and chronic liver disease.The DRs are thought to be the transit amplifying cells deriving from activation of the stem/progenitor cell compartments of the liver. The aim of this study was to examine the presence of proliferative index of DR (PI-DR) and HPC markers' expression in HCCs after curative hepatectomy, as well as their relationship with clinicopathological features and prognosis.

Results: Tissue microarray with peritumoral and intratumoral tissue samples of 120 HCCs after hepatectomy was analysed for peritumoral expression of proliferating cell nuclear antigen for PI-DR. Peritumoral and intratumoral expression status of HPC markers including EpCAM, OV6, CD133 and c-kit were also examined by immunohistochemistry. TMA analysis of HCCs revealed that peritumoral PI-DR strongly correlated with the degree of inflammation and fibrosis. The peritumoral PI-DR positively correlated with peritumoral HPC markers EpCAM, OV6, CD133 and c-kit expression. Moreover, there were highly significant correlations between peritumoral PI-DR and intratumoral HPC markers EpCAM, OV6, CD133 and c-kit expression. Further, multivariate analysis showed that peritumoral PI-DR was the independent prognostic factor for overall survival (HR; 3.316, $P<0.001)$, and peritumoral PI-DR had a better power to predict disease-free survival (HR; 2.618, $P<0.001)$.
\end{abstract}

Conclusions: Peritumoral PI-DR, as a valid surrogate for peritumoral and intratumoral expression of HPC markers, could be served as a potential prognostic marker for recurrence and survival in HCC after hepatectomy.

Keywords: Proliferative index of ductular reaction, Hepatic progenitor cell, Recurrence, Hepatocellular carcinoma

\section{Introduction}

Hepatocellular carcinoma (HCC) is one of the main concerns in global health care which is difficult to cure because of recurrence after resection [1,2]. Most research has been focused on the discovery of specific markers useful for $\mathrm{HCC}$ diagnosis and prognostic prediction to provide scientific guidance to clinical management $[3,4]$. Recently, a number of investigations have demonstrated that the involvement of a ductular reaction (DR), which is a reactive lesion at the portal tract interface comprising increased bile ductules with an accompanying

\footnotetext{
* Correspondence: weilixin_smmu@163.com

${ }^{\dagger}$ Equal contributors

${ }^{1}$ Tumor Immunology and Gene Therapy Center, Eastern Hepatobiliary Surgery Hospital, The Second Military Medical University, Shanghai, China Full list of author information is available at the end of the article
}

complex of stromal and inflammatory cells, has been implicated in the pathogenesis of progressive fibrosis, regeneration and hepato-carcinogenesis in chronic liver disease $[5,6]$. The main epithelial component of DR are reactive ductule cells (RDCs) with biliary/HPC phenotype arranged in an irregularly shaped structure residing along parenchymal-stromal boundaries. The RDCs are pathological, proliferative, biliary epithelial cell-like cells formed during repair process after liver injury, and are able to secrete various cytokines and chemokines, which interact with microenvironment [7]. In previous studies, we have reported that peritumoral DR in a necroinflammatory microenvironment was a poor prognostic factor for $\mathrm{HCC}$ after resection [8]. However, the role of the proliferation status of DR remains elusive in HCC. 
Ductular reaction is known to be present in most chronic liver diseases, but it seems especially important in hepatic stem and progenitor cells in liver regeneration mechanisms underlying hepatic fibrosis, and hepatobiliary carcinogenesis. Although not well described, however, when there is either massive liver injury or chronic liver damage that compromise the proliferative capacity of hepatocytes, progenitor cells within the Canal of Hering start to proliferate, giving rise to what is known as ductular reaction $[9,10]$. The hepatic progenitor cells (HPCs) have been identified in the human liver as bipotential cells capable of proliferation and differentiation into both hepatocellular and biliary cell lineages $[11,12]$. HPCs are reportedly recognized as cells smaller than normal hepatocytes, and present as a single cell or strings of a few such cells in periportal or periseptal regions of regenerative nodules or hepatic lobules. HPCs express biliary markers (such as OV6 and EpCAM), and a subset of these cells expresses hematopoietic markers (such as the receptor for stem cell factor c-kit [KIT] and prominin-1 [PROM1]/CD133) [13-16]. In additon, HCCs expressing HPC markers are likely to have significantly more negative prognosis and a higher recurrence after surgical resection and liver transplantation $[17,18]$. To the best of our knowledge, the significance of the proliferative DR (PI-DR) and the correlation between PIDR and the expression of HPC markers in terms of HCC prognosis has not been studied in detail.

Therefore, we performed a clinicopathological study on 120 cases who had undergone hepatectomy for histologically proven $\mathrm{HCC}$, using the tissue microarray containing paired peritumoral and intratumoral liver specimens, we quantified the proliferative index of DR (PI-DR) in the peritumoral tissue. In addition, immunohistochemical detection of peritumoral and intratumoral HPC markers were performed to investigate the relationship between PI-DR and HPCs in detail. Moreover, we further explore the role of PI-DR in the HCC prognostic prediction after curative resection and their clinical relevance.

\section{Results}

\section{Clinico-pathological features}

The clinical and histological data are summarized in Table 1 . Among the 120 subjects with pathological specimens available for assessment, 108 (90.0\%) were male. This table also details the distribution of subjects within each grade of inflammation and stage of fibrosis. At the time of the last follow-up, 111 patients had tumor recurrence and 76 patients had died, and all patients died with a record of tumor recurrence. Among patients undergoing curative resections $(\mathrm{n}=120)$ the $1-, 3-$, and 5 -year overall survival (OS) rates were 92.3\%, 46.4\%, and $32.6 \%$, respectively, and the 1-, 3-, and 5-year disease- free survival (DFS) rates were 70.7\%, 14.7\%, and 9.6\%, respectively.

\section{Peritumoral proliferative ductular reaction (PI-DR) is present in $\mathrm{HCC}$ and correlates with the degree of inflammation and fibrosis}

As reported, the ductular reaction (DR) was positive uniformly and strongly for cytokeratin 7 staining [12]. In peritumoral K7 staining sections of the entire tissue microarray group, DR was frequently found in the fibrous septa and the enlarged periportal areas in HCC patients (Figure 1A). Further, In terms of PI-DR, the proliferating cell nuclear antigen (PCNA) was labeled for the proliferation status of DR (Figure 1B). 37 of 120 patients $(30.8 \%)$ had PI-DR $\geq 50 \%$.

Previous studies have shown that DRs correlate with the degree of inflammation and fibrosis in the course of many chronic human liver diseases $[9,10]$. Thus, we evaluated the liver necroinflammation and fibrosis and their association with PI-DR. Consistent with prior studies, we observed PI-DR correlated with hepatic necroinflammation grade $(\mathrm{r}=0.614, \quad P<0.001$, Figure $1 \mathrm{C})$. Correlations were also found between PI-DR and fibrosis stage $(r=0.527, P<0.001$, Figure $1 D)$.

\section{Expression of hepatic progenitor cell markers in peritumoral tissue of HCC patients and clinicopathologic correlations:relationship with peritumoral PI-DR}

Several markers, including EpCAM, OV6, CD133 and ckit, which are expressed as markers for hepatic progenitor cells (HPCs), have been considered to be the origin of HCCs [19]. However, the link between PI-DR and expression of HPC markers has not been fully elucidated. We firstly conducted an immunohistochemical analysis of four HPC markers (EpCAM, OV6, CD133 and c-kit) in the peritumoral tissue sections of the entire group, the high EpCAM, OV6, CD133 and c-kit expression was seen in 40 of 120 (33.3\%), 34 of 120 (28.3\%), 33 of 120 (27.5\%), and 39 of 120 (32.5\%) cases, respectively (Table 2). EpCAM expression was seen in the membrane and cytoplasm of cholangiocytes of all branches of the biliary tree, including canals of Hering, ductules, and small and large bile ducts. The ductular OV-6-positive cells with a more transitional morphology, represented small numbers of individual oval-like cells adjacent to ducts in marginal regions. CD133-positive cells were mostly accumulated as patches with granular appearance in the cytoplasm of a few scattered hepatocytes. C-kit positive cells were diffused in the parenchyma in HCCs (Figure 2A).

HCCs were grouped according to the expression status of peritumoral HPC markers, and clinicopathological parameters were further analyzed. As shown in Table 2, patients with a high peritumoral EpCAM and 


\begin{tabular}{|c|c|c|}
\hline Factors & Value & Percent \\
\hline \multicolumn{3}{|c|}{ Demographic characteristics } \\
\hline Age & $50.1 \pm 11.9$ & \\
\hline Gender (male/female) & $108 / 12$ & $90.0 / 10.0$ \\
\hline \multicolumn{3}{|l|}{ Tumor characteristics } \\
\hline Maximum tumor diameter & $6.9 \pm 4.2$ & \\
\hline Tumor encapsulation & 33 & 27.5 \\
\hline Tumor number (multiple)* & 15 & 12.5 \\
\hline Microvascular invasion & 65 & 54.2 \\
\hline Major vascular invasion & 6 & 5.0 \\
\hline \multicolumn{3}{|l|}{ Edmondson grade } \\
\hline $\operatorname{Low}(I / I I)$ & 90 & 75.0 \\
\hline High (III/IV) & 30 & 25.0 \\
\hline \multicolumn{3}{|l|}{ TNM stage } \\
\hline$|/| \mid$ & 92 & 76.7 \\
\hline III & 28 & 23.3 \\
\hline \multicolumn{3}{|c|}{ Histology of chronic liver disease } \\
\hline \multicolumn{3}{|c|}{ Necroinflammation grade (score) } \\
\hline No $(0)$ & 0 & 0.0 \\
\hline Minimal (1-4) & 6 & 5.0 \\
\hline Mild (5-8) & 38 & 31.7 \\
\hline Moderate (9-12) & 57 & 47.5 \\
\hline Marked (13-18) & 19 & 15.8 \\
\hline \multicolumn{3}{|l|}{ Fibrosis stage } \\
\hline 0 & 4 & 3.3 \\
\hline $1-4$ & 67 & 55.8 \\
\hline $5-6$ & 49 & 40.9 \\
\hline \multicolumn{3}{|l|}{ Laboratory values } \\
\hline AFP $(\mathrm{ng} / \mathrm{mL})$ & $351.0 \pm 414.1(1.7-1000.0)$ & \\
\hline CEA (ng/mL) & $4.3 \pm 7.1(0.0-58.2)$ & \\
\hline CA19-9 (U/mL) & $15.8 \pm 14.4(0.0-120.8)$ & \\
\hline $\mathrm{ALT}(\mathrm{U} / \mathrm{L})$ & $54.6 \pm 37.2(9.8-234.9)$ & \\
\hline AST (IU/L) & $39.5 \pm 19.4(2.0-108.3)$ & \\
\hline
\end{tabular}

Abbreviations: AFP alpha-fetoprotein; CEA carcinoembryonic antigen; CA19-9 carbohydrate antigen 19-9; ALT alanine aminotransferase; AST aspartate aminotransferase; TNM tumor-node-metastasis.

*Multifocal tumors diagnosed by preoperative image finding.

CD133 expression level were more prone to have high TNM stage, high Edmondson grade in patients with the high peritumoral OV6 expression, and high peritumoral c-kit expression patients demonstrated more cirrhosis.

Next, we further identify the correlation between PI-DR and the peritumoral HPC markers' expression (IOD). PI-DR had a positive correlation with EpCAM $(r=0.441$, $P<0.001)$, OV6 $(\mathrm{r}=0.342, P<0.001)$, CD133 $(\mathrm{r}=0.408$, $P<0.001)$ and $\mathrm{c}-\mathrm{kit}$ expression $(\mathrm{r}=0.291, \quad P=0.001)$ (Figure $2 \mathrm{~B}$ ) in peritumoral tissue of the entire group.
These findings support the concept that proliferative DR in peritumoral environment may contribute to activation of progenitor cells and related carcinogenesis.

\section{Peritumoral PI-DR as a valid surrogate for intratumoral expression of HPC markers}

To assess if the intratumoral expression of HPC markers were correlated with PI-DR in our study, we further performed an IHC analysis of four HPC markers (EpCAM, OV6, CD133 and c-kit) in the intratumoral tissue sections of the entire group as shown in Figure 3A, the high 


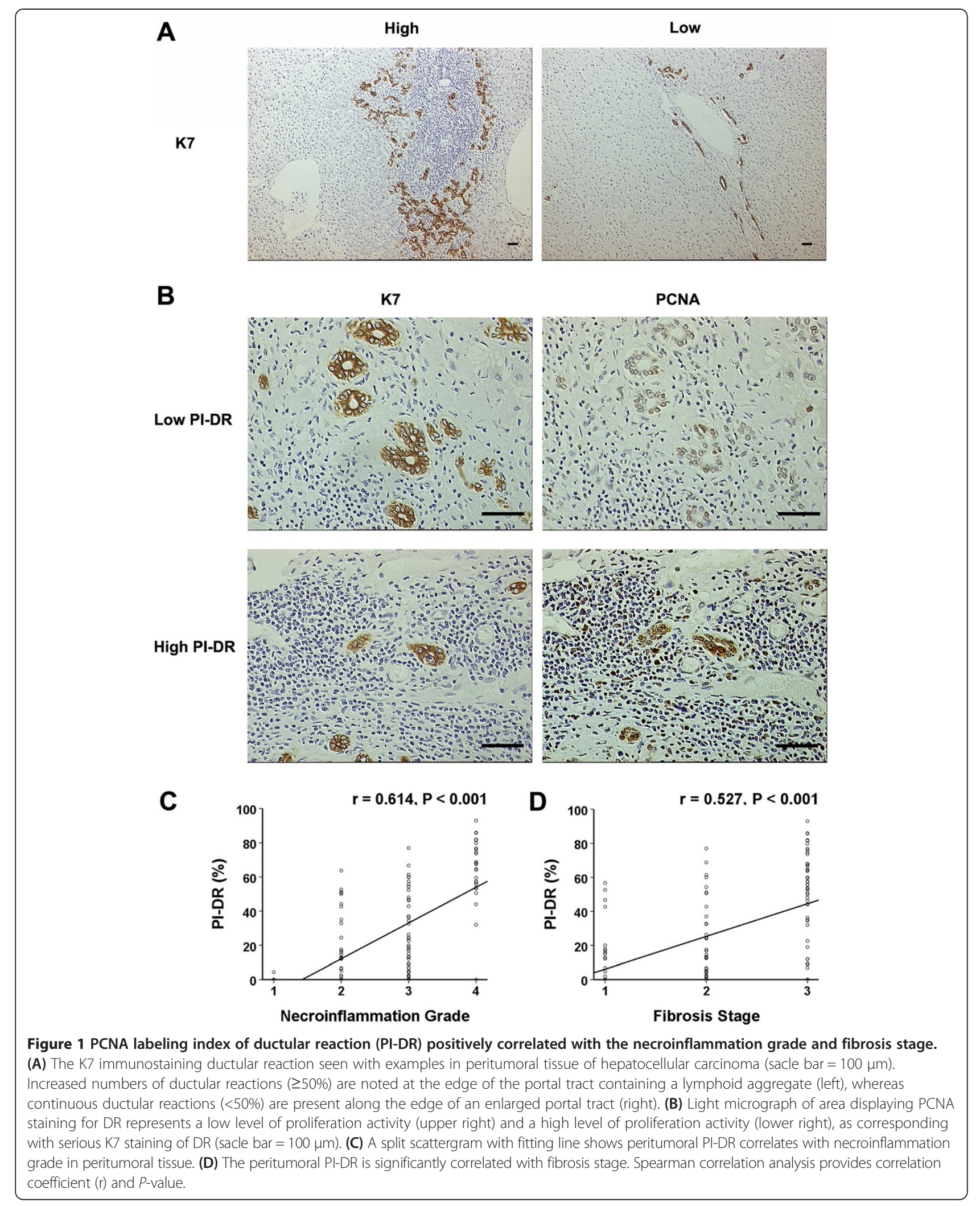


Table 2 Immunohistochemical stain results and clinicopathologic features in peritumoral tissue of 120 HCCs

\begin{tabular}{|c|c|c|c|c|c|c|c|c|c|c|c|c|}
\hline \multirow[t]{2}{*}{$\begin{array}{l}\text { Clinicopathologic } \\
\text { features }\end{array}$} & \multicolumn{2}{|c|}{$\begin{array}{c}\text { Peritumoral } \\
\text { EpCAM density }\end{array}$} & \multirow[t]{2}{*}{$\begin{array}{c}P \\
\text { Value }\end{array}$} & \multicolumn{2}{|c|}{$\begin{array}{l}\text { Peritumral } \\
\text { OV6 density }\end{array}$} & \multirow[t]{2}{*}{$\begin{array}{c}P \\
\text { Value }\end{array}$} & \multicolumn{2}{|c|}{$\begin{array}{c}\text { Peritumral } \\
\text { CD133 density }\end{array}$} & \multirow[t]{2}{*}{$\begin{array}{c}P \\
\text { Value }\end{array}$} & \multicolumn{2}{|c|}{$\begin{array}{c}\text { Peritumral } \\
\text { c-kit density }\end{array}$} & \multirow[t]{2}{*}{$\begin{array}{c}P \\
\text { Value }\end{array}$} \\
\hline & High & Low & & High & Low & & High & Low & & High & Low & \\
\hline Frequency (\%) & $\begin{array}{c}40 \\
(33.3 \%)\end{array}$ & $\begin{array}{c}80 \\
(66.7 \%)\end{array}$ & & $\begin{array}{c}34 \\
(28.3 \%)\end{array}$ & $\begin{array}{c}86 \\
(71.7 \%)\end{array}$ & & $\begin{array}{c}33 \\
(27.5 \%)\end{array}$ & $\begin{array}{c}87 \\
(72.5 \%)\end{array}$ & & $\begin{array}{c}39 \\
(32.5 \%)\end{array}$ & $\begin{array}{c}81 \\
(67.5 \%)\end{array}$ & \\
\hline \multicolumn{13}{|l|}{ Gender } \\
\hline Male & 35 & 73 & 0.747 & 30 & 78 & 0.946 & 30 & 78 & 1.000 & 37 & 71 & 0.363 \\
\hline Female & 5 & 7 & & 4 & 8 & & 3 & 9 & & 2 & 10 & \\
\hline \multicolumn{13}{|l|}{ Age } \\
\hline$\leq 50$ & 21 & 42 & 1.000 & 16 & 47 & 0.453 & 19 & 44 & 0.493 & 20 & 43 & 0.853 \\
\hline$>50$ & 19 & 38 & & 18 & 39 & & 14 & 43 & & 19 & 38 & \\
\hline \multicolumn{13}{|l|}{ AFP } \\
\hline$\leq 400$ & 25 & 56 & $0 . .408$ & 22 & 59 & 0.681 & 23 & 58 & 0.752 & 24 & 57 & 0.333 \\
\hline$>400$ & 15 & 24 & & 12 & 27 & & 10 & 29 & & 15 & 24 & \\
\hline \multicolumn{13}{|l|}{ Cirrhosis } \\
\hline Absence & 20 & 51 & 0.149 & 19 & 52 & 0.645 & 17 & 54 & 0.294 & 17 & 54 & $0.016^{*}$ \\
\hline Presence & 20 & 29 & & 15 & 34 & & 16 & 33 & & 22 & 27 & \\
\hline \multicolumn{13}{|l|}{ Satellite lesion } \\
\hline Absence & 36 & 69 & 0.770 & 28 & 77 & 0.284 & 29 & 76 & 1.000 & 35 & 70 & 0.606 \\
\hline Presence & 4 & 11 & & 6 & 9 & & 4 & 11 & & 4 & 11 & \\
\hline \multicolumn{13}{|l|}{ Tumor size (cm) } \\
\hline$\leq 5 \mathrm{~cm}$ & 15 & 37 & 0.362 & 15 & 37 & 0.913 & 16 & 36 & 0.483 & 18 & 34 & 0.665 \\
\hline$>5 \mathrm{~cm}$ & 25 & 43 & & 19 & 49 & & 17 & 51 & & 21 & 47 & \\
\hline \multicolumn{13}{|l|}{ Tumor encapsulation } \\
\hline Absence & 26 & 61 & 0.193 & 26 & 61 & 0.540 & 23 & 64 & 0.672 & 27 & 60 & 0.578 \\
\hline Presence & 14 & 19 & & 8 & 25 & & 10 & 23 & & 12 & 21 & \\
\hline \multicolumn{13}{|c|}{ Microvascular invasion } \\
\hline Absence & 17 & 38 & 0.604 & 17 & 38 & 0.565 & 18 & 37 & 0.238 & 22 & 33 & 0.107 \\
\hline Presence & 23 & 42 & & 17 & 48 & & 15 & 50 & & 17 & 48 & \\
\hline \multicolumn{13}{|l|}{$\begin{array}{l}\text { Major vascular } \\
\text { invasion }\end{array}$} \\
\hline Absence & 39 & 75 & 0.657 & 33 & 81 & 0.853 & 29 & 85 & 0.083 & 38 & 76 & 0.687 \\
\hline Presence & 1 & 5 & & 1 & 5 & & 4 & 2 & & 1 & 5 & \\
\hline \multicolumn{13}{|l|}{ Edmondson grade } \\
\hline Low $(I / I I)$ & 27 & 63 & 0.180 & 21 & 69 & $0.035^{*}$ & 23 & 67 & 0.409 & 28 & 62 & 0.574 \\
\hline High (III/IV) & 13 & 17 & & 13 & 17 & & 10 & 20 & & 11 & 19 & \\
\hline \multicolumn{13}{|l|}{ TNM stage } \\
\hline$|/| \mid$ & 25 & 67 & $0.009^{*}$ & 23 & 69 & 0.142 & 16 & 76 & $<0.001^{*}$ & 29 & 63 & 0.678 \\
\hline III & 15 & 13 & & 11 & 17 & & 17 & 11 & & 10 & 18 & \\
\hline
\end{tabular}

${ }^{*} p<0.05$ was considered statistically significant.

intratumoral expression of EpCAM, OV6, CD133 and ckit was seen in 39 of 120 (32.5\%), 26 of 120 (21.7\%), 29 of $120(24.2 \%)$, and 34 of $120(28.3 \%)$ cases, respectively (Table 3).

HCCs were grouped according to intratumoral HPC expression, and clinicopathological features were compared as shown in the Table 3. High intratumoral
EpCAM was significantly associated with more major vascular invasion $(P=0.023)$, high $\operatorname{AFP}(P<0.001)$ and high Edmondson grade $(P=0.005)$, High intratumoral OV6 expression of the entire group demonstrated more cirrhosis $(P=0.015)$. High intratumoral c-kit expression was significantly more likely to occur in high Edmondson grade $(P=0.010)$. 

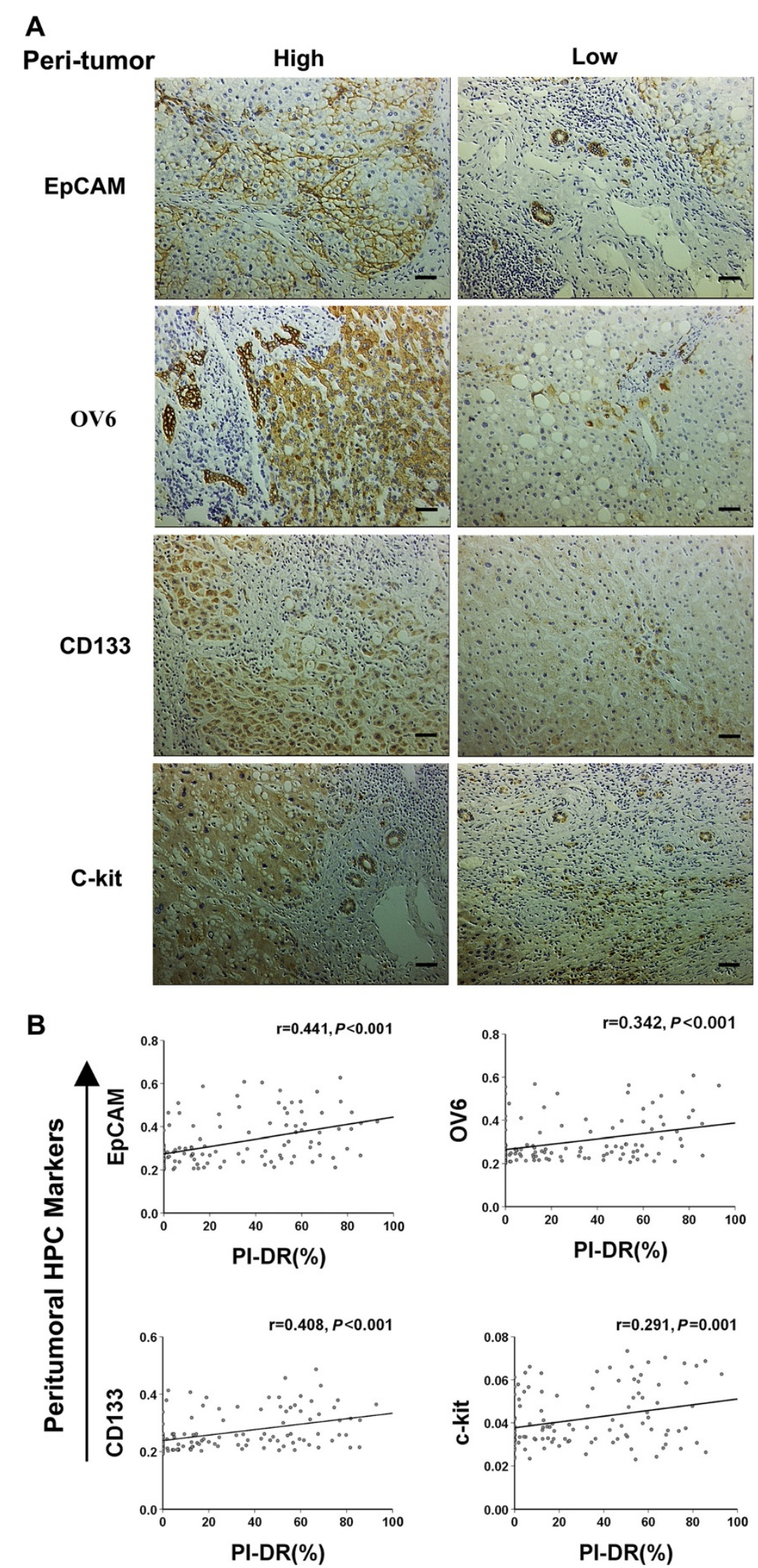

Figure $\mathbf{2}$ (See legend on next page.) 
(See figure on previous page.)

Figure 2 The peritumoral PI-DR positively correlates with the peritumoral expression of HPC markers. (A) Photographs of immunostaining of hepatic progenitor cell markers in peritumoral sections of tissue microarrays were taken for analyses (sacle bar = $100 \mu \mathrm{m}$ ). High and low density of EpCAM, OV6, CD133 and c-kit expression in peritumoral sections. (B) Scatterplot with fitting line shows peritumoral PI-DR positively correlates with peritumoral EpCAM, OV-6, CD133 and c-kit expression measured by IOD. Pearson correlation analysis provides correlation coefficient ( $r$ ) and P-value.

We further analyzed the correlation of PI-DR with the intratumoral HPC markers' expression (IOD). PI-DR had a positive correlation with intratumoral EpCAM ( $\mathrm{r}=$ 0.328, $P<0.001$, OV6 ( $\mathrm{r}=0.466, P<0.001)$, CD133 ( $\mathrm{r}=$ $0.356, P<0.001)$ and $c-k i t$ expression $(\mathrm{r}=0.398, P<0.001)$ (Figure $3 \mathrm{~B}$ ) in the entire group. Thus, together these results suggest that PI-DR could be used as a valid surrogate for intratumoral expression of HPC markers.

\section{The association of peritumoral high PI-DR in HCC with poor disease-free survival}

The survival of the selected HCC patients was analyzed with Kaplan-Meier survival analysis. Patients with high PI-DR ( $\geq 50 \%$ ) were likely to be with significantly poor OS and DFS. The median (95\% CI) overall survival time was 25.3 (21.7-28.8) and 48.8 (31.3-66.3) months respectively for patients with high PI-DR $(\geq 50 \%)$ and low PI-DR $(<50 \%)$ in HCC $(P<0.001$, Figure $4 \mathrm{~A})$. The median $(95 \% \mathrm{CI})$ disease-free survival time was 10.1 (7.0 $13.2)$ and $21.2(18.4$ - 24.1) months respectively for patients with high PI-DR $(\geq 50 \%)$ and low PI-DR $(<50 \%)$ in HCC $(P<0.001$, Figure 4B).

\section{Univariate and multivariate analyses of prognostic variables in HCC patients}

In univariate analysis, PI-DR ( $\geq 50 \%$ vs $<50 \%)$, K7-DR ( $\geq 50 \%$ vs $<50 \%$ ), TNM stage (I/II vs. III), macrovascular invasion (presence vs. absence) and intratumoral EpCAM Expression (High vs. Low) showed a significant association with poor overall survival $(P<0.001, P=0.045, P=0.030$, $P=0.014$ and $P=0.017$ respectively, Table 4$)$. Univariable analysis also revealed that PI-DR $(P<0.001)$, TNM stage (I/II vs. III) $(P=0.001)$, Edmondson grade (I/II vs. III/IV) $(P=0.043)$, peritumoral EpCAM expression (High vs. Low) $(P=0.003)$, peritumoral CD133 expression (High vs. Low) $(P<0.001)$, intratumoral OV6 expression (High vs. Low) $(P=0.034)$ were independent prognostic factors for DFS after resection (Table 4 ).

Factors showing significance by univariate analysis were adopted when multivariate Cox proportional hazards analysis was performed (Table 4). PI-DR (HR: 3.316, 95\% CI: 1.961 - 5.610, $P<0.001$ ), K7-DR (HR: 1.863, 95\% CI: $1.008-3.443, P=0.047)$ were independent prognostic factors for overall survival. Moreover, PI-DR (HR: 2.618, 95\% CI: $1.701-4.029, P<0.001)$ and TNM stage (HR: 1.817, 95\% CI: $1.135-2.909, P=0.013$ ) were also independent predictors for disease-free survival.

\section{Discussion}

The main findings of our study are that in a cohort of patients with HCC (1) the peritumoral proliferative index of DR (PI-DR) stained with PCNA is observed within the HCCs and the PI-DR correlates closely with the necroinflammation grade and fribrosis stage. (2) The PI-DR correlates strongly with the expression of peritumoral and intratumoral HPC markers in HCC patients. (3) PI-DR is the independent risk factor for both DFS and OS in HCCs.

It is well known that the important consequences of the ductular reaction are inflammatory infiltration, rich in neutrophil inflitration (cholangiolitis), periportal fibrosis and neovascularization [20]. The extensive analysis supported that the DRs correlated closely with severity of fibrosis across a range of liver pathologies including chronic hepatitis C, alcoholic and non-alcoholic steatohepatitis, and fibrosing cholestatic hepatitis [12]. In our study, that is also evidenced by high levels of proliferation rate within DRs strongly correlating with necroinflammation and fibrosis in HCC patients. Our study does not prove that the proliferative ductular reaction directly promote necroinflammation and fibrosis, or that the reaction is simply a by-product of necroinflammation and fibrosis. Clouston [9] and colleagues found that the presence of a fine ductular reaction in some patients without portal fibrosis, may suggest that the ductular reaction itself may be important in the development of fibrosis.

In normal liver undergoing partial hepatectomy or acute injury, hepatocyte-mediated regeneration predominates. In chronic and severe injury, however, ductular reactions (DRs) of activated biliary epithelial cells which contain hepatic progenitor cells (HPCs) appear in the periportal regions. In our study, we studied the proliferative state of ductular reaction, with PCNA as a proliferation marker, to test the hypothesis that whether the proliferative ductular reaction (PI-DR) correlated with the expression of peritumoral and intratumoral HPC markers. We identified PI-DR had positive correlations with EpCAM, OV6, CD133 and c-kit expression in both peritumoral and intratumoral tissue of the entire group. Our data indicated that proliferative ductular reaction could serve as a valid surrogate for peritumoral and intratumoral expression of HPC markers. Consistent with our findings, Cai et al. [21] have found that proliferative ductular reaction is related to HPC activation in patients with combined hepatocellular-cholangiocarcinoma. Lennerz and colleagues [22] suggested marked alterations in cellular 


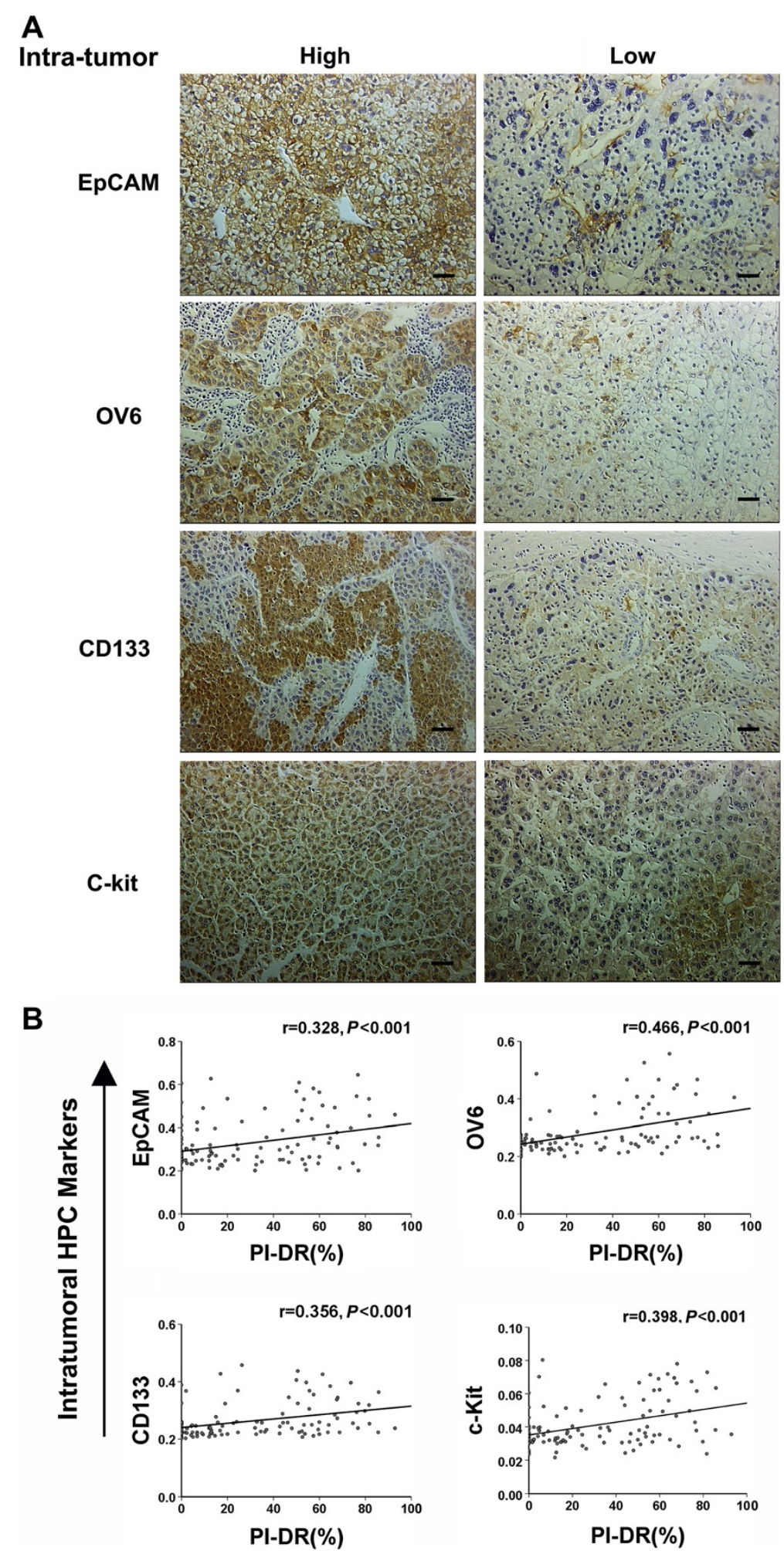

Figure 3 The peritumoral PI-DR positively correlates with the intratumoral HPC markers expression. (A) Photographs of immunostaining of hepatic progenitor cell markers in intratumoral sections of tissue microarrays were taken for analyses (sacle bar $=100 \mu \mathrm{m}$ ). High and low density of EpCAM, OV6, CD133 and c-kit expression in intratumoral sections. (B) Scatterplot with fitting line shows peritumoral PI-DR positively correlates with the intratumoral EpCAM, OV-6, CD133 and c-kit expression measured by IOD. Pearson correlation analysis provides correlation coefficient ( $r$ ) and $P$-value (right). 
Table 3 Immunohistochemical stain results and clinicopathologic features in intratumoral tissue of 120 HCCs

\begin{tabular}{|c|c|c|c|c|c|c|c|c|c|c|c|c|}
\hline \multirow[t]{2}{*}{$\begin{array}{l}\text { Clinicopathologic } \\
\text { features }\end{array}$} & \multicolumn{2}{|c|}{$\begin{array}{c}\text { Intratumoral } \\
\text { EpCAM density }\end{array}$} & \multirow[t]{2}{*}{$\begin{array}{c}P \\
\text { Value }\end{array}$} & \multicolumn{2}{|c|}{$\begin{array}{l}\text { Intratumoral } \\
\text { OV6 density }\end{array}$} & \multirow[t]{2}{*}{$\begin{array}{c}P \\
\text { Value }\end{array}$} & \multicolumn{2}{|c|}{$\begin{array}{c}\text { Intratumoral } \\
\text { CD133 density }\end{array}$} & \multirow[t]{2}{*}{$\begin{array}{c}P \\
\text { Value }\end{array}$} & \multicolumn{2}{|c|}{$\begin{array}{l}\text { Intratumoral } \\
\text { c-kit density }\end{array}$} & \multirow[t]{2}{*}{$\begin{array}{c}P \\
\text { Value }\end{array}$} \\
\hline & High & Low & & High & Low & & High & Low & & High & Low & \\
\hline Frequency (\%) & $\begin{array}{c}39 \\
(32.5 \%)\end{array}$ & $\begin{array}{c}81 \\
(67.5 \%)\end{array}$ & & $\begin{array}{c}26 \\
(21.7 \%)\end{array}$ & $\begin{array}{c}94 \\
(78.3 \%)\end{array}$ & & $\begin{array}{c}29 \\
(24.2 \%)\end{array}$ & $\begin{array}{c}91 \\
(75.8 \%)\end{array}$ & & $\begin{array}{c}34 \\
(28.3 \%)\end{array}$ & $\begin{array}{c}86 \\
(71.7 \%)\end{array}$ & \\
\hline \multicolumn{13}{|l|}{ Gender } \\
\hline Male & 34 & 74 & 0.697 & 21 & 87 & 0.161 & 26 & 82 & 1.000 & 32 & 76 & 0.543 \\
\hline Female & 5 & 7 & & 5 & 7 & & 3 & 9 & & 2 & 10 & \\
\hline \multicolumn{13}{|l|}{ Age } \\
\hline$\leq 60$ & 19 & 44 & 0.565 & 19 & 62 & 0.493 & 13 & 50 & 0.342 & 19 & 44 & 0.641 \\
\hline$>60$ & 20 & 37 & & 7 & 32 & & 16 & 41 & & 15 & 42 & \\
\hline \multicolumn{13}{|l|}{ AFP } \\
\hline$\leq 400$ & 17 & 64 & $<0.001^{*}$ & 19 & 62 & 0.493 & 20 & 61 & 0.847 & 23 & 58 & 0.983 \\
\hline$>400$ & 22 & 17 & & 7 & 32 & & 9 & 30 & & 11 & 28 & \\
\hline \multicolumn{13}{|l|}{ Cirrhosis } \\
\hline Absence & 21 & 50 & 0.411 & 10 & 61 & $0.015^{*}$ & 14 & 57 & 0.171 & 17 & 54 & 0.199 \\
\hline Presence & 18 & 31 & & 16 & 33 & & 15 & 34 & & 17 & 32 & \\
\hline \multicolumn{13}{|l|}{ Satellite lesion } \\
\hline Absence & 33 & 72 & 0.507 & 22 & 83 & 0.867 & 27 & 78 & 0.468 & 33 & 72 & 0.092 \\
\hline Presence & 6 & 9 & & 4 & 11 & & 2 & 13 & & 1 & 14 & \\
\hline \multicolumn{13}{|l|}{ Tumor size (cm) } \\
\hline$\leq 5 \mathrm{~cm}$ & 15 & 37 & 0.455 & 14 & 38 & 0.222 & 13 & 39 & 0.852 & 12 & 40 & 0.264 \\
\hline$>5 \mathrm{~cm}$ & 24 & 44 & & 12 & 56 & & 16 & 52 & & 22 & 46 & \\
\hline \multicolumn{13}{|c|}{ Tumor encapsulation } \\
\hline Absence & 26 & 61 & 0.321 & 18 & 69 & 0.673 & 19 & 68 & 0.334 & 27 & 60 & 0.286 \\
\hline Presence & 13 & 20 & & 8 & 25 & & 10 & 23 & & 7 & 26 & \\
\hline \multicolumn{13}{|c|}{ Microvascular invasion } \\
\hline Absence & 15 & 40 & 0.261 & 14 & 41 & 0.354 & 12 & 43 & 0.580 & 17 & 38 & 0.565 \\
\hline Presence & 24 & 41 & & 12 & 53 & & 17 & 48 & & 17 & 48 & \\
\hline \multicolumn{13}{|l|}{$\begin{array}{l}\text { Major vascular } \\
\text { invasion }\end{array}$} \\
\hline Absence & 34 & 80 & $0.023^{*}$ & 25 & 89 & 1.000 & 28 & 86 & 1.000 & 32 & 82 & 1.000 \\
\hline Presence & 5 & 1 & & 1 & 5 & & 1 & 5 & & 2 & 4 & \\
\hline \multicolumn{13}{|l|}{ Edmondson grade } \\
\hline $\operatorname{Low}(I / I I)$ & 23 & 67 & $0.005^{*}$ & 17 & 73 & 0.201 & 19 & 71 & 0.176 & 20 & 70 & $0.010^{*}$ \\
\hline High (III/IV) & 16 & 14 & & 9 & 21 & & 10 & 20 & & 14 & 16 & \\
\hline \multicolumn{13}{|l|}{ TNM stage } \\
\hline |/II & 27 & 65 & 0.181 & 17 & 75 & 0.124 & 20 & 72 & 0.260 & 28 & 64 & 0.354 \\
\hline III & 12 & 16 & & 9 & 19 & & 9 & 19 & & 6 & 22 & \\
\hline
\end{tabular}

${ }^{*} p<0.05$ was considered statistically significant.

identity as an underlying mechanism for the reproducible perinodular DR that parallels progressive stages of intranodular hepatocarcinogenesis. Several studies have also shown that high levels of proliferation rate within DRs has been demonstrated in both oval cellmediated liver regeneration in an animal model and human liver disease $[23,24]$. The other published studies have shown that ductular reaction is frequently associated with fibrosis and inflammation in chronic liver disease and may be key factors promoting liver progenitor cell expansion in alcoholic hepatitis [25]. Delladetsima et al. [26] have reported a periportal ductular reaction was noted in association with HPC expansion in $\mathrm{HCV}$. 

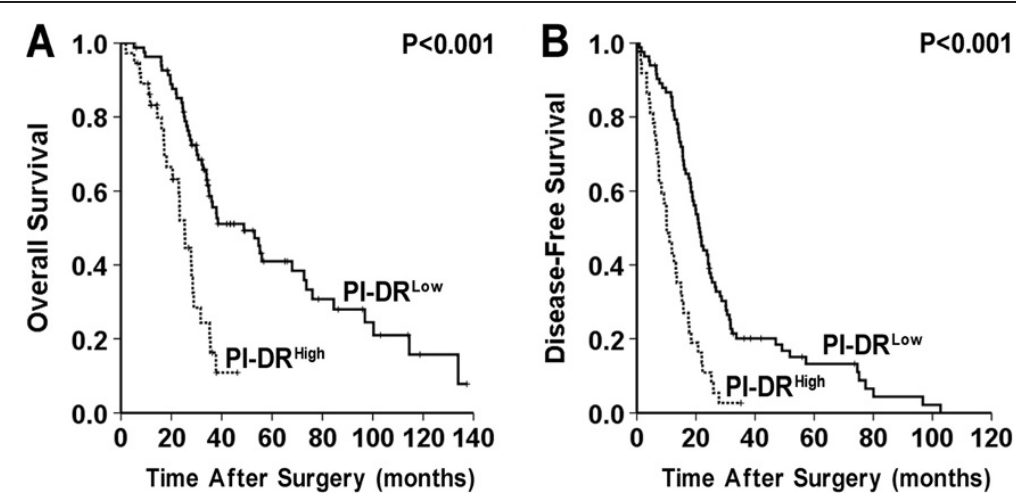

Figure 4 Cumulative overall and disease-free survival curves of HCC patients with high or low PI-DR. (A) Low PI-DR in peritumoral tissue was associated with prolonged overall survival. (B) High PI-DR in peritumoral tissue was associated with poor disease-free survival. Low PI-DR: (<50\%); High PI-DR ( $\geq 50 \%)$.

Table 4 Univariate and multivariate analyses of factors associated with survival and recurrence in hepatocellular carcinoma group of testing cohort $(n=120)$

\begin{tabular}{|c|c|c|c|c|c|c|c|}
\hline \multirow[t]{3}{*}{ Factors } & & \multirow{3}{*}{$\begin{array}{c}\text { Univariate } \\
\qquad P\end{array}$} & \multirow{2}{*}{\multicolumn{2}{|c|}{$\begin{array}{c}\text { Overall Survival (OS) } \\
\text { Multivare }\end{array}$}} & \multicolumn{3}{|c|}{ Disease-free Survival (DFS) } \\
\hline & & & & & \multicolumn{3}{|c|}{$\begin{array}{ll}\text { Univariate } & \text { Multivariate }\end{array}$} \\
\hline & & & HR $(95 \% \mathrm{Cl})$ & $P$ & $P$ & $\mathrm{HR}(95 \% \mathrm{Cl})$ & $P$ \\
\hline Characteristic of & Age: $>50$ vs. $\leq 50$ years* & 0.719 & & NA & 0.981 & & NA \\
\hline Demography, & Gender: male vs. female & 0.846 & & NA & 0.088 & & NA \\
\hline Tumor \& & Tumor size: $>5$ vs. $\leq 5 \mathrm{~cm}$ & 0.061 & & NA & 0.130 & & NA \\
\hline Laboratory & Tumor number: multiple vs. single & 0.221 & & NA & 0.192 & & NA \\
\hline \multirow[t]{6}{*}{ Tests } & Serum AFP: $\geq 400$ vs. $<400$ ng/ml & 0.285 & & NA & 0.382 & & NA \\
\hline & Serum CA199 $\geq 37$ vs. $<37 \mathrm{U} / \mathrm{ml}$ & 0.798 & & NA & 0.236 & & NA \\
\hline & TNM stage: I/II vs. III & $0.030^{*}$ & & NS & $0.001^{*}$ & $1.817(1.135-2.909)$ & $0.013^{*}$ \\
\hline & Edmondson grade: I/II vs. III/IV & 0.074 & & NA & $0.043^{*}$ & & NS \\
\hline & Macrovascular Invasion: P vs. N & $0.014^{*}$ & & NS & 0.114 & & NA \\
\hline & Tumor encapsulation: absence vs. presence & 0.791 & & NA & 0.311 & & NA \\
\hline Histology: & Ishak grade $>7$ vs. $\leq 7$ & 0.058 & & NA & 0.072 & & NA \\
\hline \multirow[t]{7}{*}{ Peritumor } & Ishak stage $>5$ vs. $\leq 5$ & 0.096 & & NA & 0.120 & & NA \\
\hline & PI-DR $\geq 50 \%$ vs. $<50 \%$ & $<0.001^{*}$ & $3.316(1.961-5.610)$ & $<0.001^{*}$ & $<0.001^{*}$ & $2.618(1.701-4.029)$ & $<0.001^{*}$ \\
\hline & K7-DR $\geq 50 \%$ vs. $<50 \%$ & $0.045^{*}$ & $1.863(1.008-3.443)$ & $0.047^{*}$ & 0.158 & & NA \\
\hline & EpCAM ${ }^{\text {Peritumor }}$ Expression $\mathrm{H}$ vs. $\mathrm{L}^{*}$ & 0.319 & & NA & $0.003^{*}$ & & NS \\
\hline & OV6 ${ }^{\text {Peritumor }}$ Expression H vs. L* & 0.191 & & NA & 0.702 & & NA \\
\hline & C-kit Peritumor Expression H vs. L* $^{*}$ & 0.721 & & NA & 0.935 & & NA \\
\hline & CD133 ${ }^{\text {Peritumor }}$ Expression H vs. $L^{*}$ & 0.051 & & NA & $<0.001^{*}$ & & NS \\
\hline Histology: & Microvascular invasion: P vs. N & 0.327 & & NA & 0.595 & & NA \\
\hline \multirow[t]{4}{*}{ Tumor: } & EpCAM Expression H vs. L* & $0.017^{*}$ & & NS & 0.093 & & NA \\
\hline & OV6 Expression H vs. L* & 0.756 & & NA & $0.034^{*}$ & & NS \\
\hline & C-kit Expression H vs. $L^{*}$ & 0.352 & & NA & 0.127 & & NA \\
\hline & CD133 Expression H vs. L* $^{*}$ & 0.394 & & NA & 0.091 & & NA \\
\hline
\end{tabular}

$P$, positive; $N$, negative; $H$, High; $L$, Low; $N A$, not adopted; $N S$, not significant; $A F P$, alpha-fetoprotein; $A L T$, alanine aminotransferase; $C A 19-9$, carbohydrate antigen 19-9; $C l$, confidence interval; $P I-D R$, proliferative index of ductular reaction; $D R$, ductular reaction; EpCAM, epithelial cell adhesion molecule; $H C C$, hepatocellular carcinoma; $H R$, hazard ratio; K7-DR, Keratin 7 immunoreactive ductular reaction; TNM, tumor-node-metastasis;

*Medians were used for cutoff values. 
In the present study, we also conducted an immunohistochemical analysis of four HPC markers (EpCAM, OV6, CD133 and c-kit) in peritumoral tissue microarray, and compared the various clinicopathologic features according to the expression status of each of these markers. In our study, univariate survival analysis demonstated that peritumoral EpCAM expression and peritumoral CD133 expression were independent predictors of disease-free survival. This stands in consistent with findings reported by Hoshida et al. [27], their group disclosed that gene expression profiles of HCC failed to yield a significant association with survival, whereas surrounding nontumoral profiles correlated with recurrence. Moreover, in our data the intratumoral expression of HPC markers' expression were also studied in the microarray tissue of the HCCs. Univariate survival analysis also demonstated that intratumoral EpCAM expression was an independent predictor of overall survival. Bae et al. [28] have also demonstrated EpCAM expression occurs at distinct nodular stage of HCC and could play an important role in HCC progression.

High incidence of intrahepatic metastasis and recurrence after resection suggested that peritumoral environment is an important but often neglected issue. In our previous study, Xu et al. [8] have uncovered peritumoral DR in a necroinflammatory microenvironment correlates with postoperative prognosis in HCC. Richardson et al. [10] found that an altered replication pathway in active nonalcoholic steatohepatitis promotes a periportal DR, which in turn may provoke progressive periportal fibrogenesis. The main finding of our study is that the peritumoral proliferative state of DR (PI-DR) is correlated with necroinflammation grade and fribrosis stage, and PI-DR may be involved in the HPC-derived carcinogenesis in the progression of HCC. Our finding are in accord with the following prior published data regarding the proliferative state of ductular reaction. Cai et al. [21] in our lab also identified that a "progenitor dominant" regeneration pattern, which is closely related with intensive transitamplifying DR, is associated with the poorest OS and DFS. Yoon et al. [29] found the cells of ductular reactions showed markedly elevated proliferation rates in patients with worsening stage of chronic hepatitis B and C. Importantly in our study, in Cox regression analysis including all clinico-pathological covariates for analysis, peritumoral PI-DR was the independent predictor for overall and disease-free survival in HCC.

Taken together, our results demonstrated that peritumoral PI-DR, strongly correlated with both the peritumoral and intratumoral HPC expression, may be associated with subsequent tumor development. PI-DR could be a useful marker for prognostic prediction of recurrence in HCC.

\section{Conclusion}

In summary, we found that in HCC patients, the peritumoral DR with higher PCNA labeling index was prone to correlate with the degree of necroinflammatory activity and the stage of fibrosis. We also demonstrated the peritumoral PI-DR correlated stongly with both the peritumoral and intratumoral expression of HPC markers, and peritumoral PI-DR predicted reccurrence in HCC after hepatectomy. These findings suggested that the PIDR which strongly correlated with HPC markers could represent an early stage of carcinogenesis in HCC , that would be targeted and could help define HCC patients at high risk for developing HCC after hepatectomy. The potential mediators of PI-DR are of great interest and warrant further study.

\section{Materials and methods}

\section{Patients and clinical data}

Archived, formalin-fixed and paraffin-embedded liver specimens used in this study were obtained from the Eastern Hepatobiliary Surgery Hospital, Shanghai, China. From January 1997 to December 2007, patients who underwent hepatectomy and who were post-operatively confirmed as hepatocellular carcinoma were recruited for prospective follow-up. Informed consent was obtained from each patient under a protocol approved by the Hospital Research Ethics Committees. The following tissue microarray included 138 pairs of intratumoral and peritumoral liver tissues from the selected HCC patients. Eighteen cases could not be analysed because of the loss of the samples during the preparation of the tissue microarray. The 120 remain study population consisted of 108 men and 12 women with a mean age of $50.1 \pm$ 11.9 years (range 11-89 years). Tumor size was based on the largest dimension of the tumor specimen. Satellite lesions were defined by the presence of 2 or more nodules including intrahepatic metastases. Microvascular invasion was determined by microscopic examination of the resected specimen, whereas macrovascular invasion was identified by macroscopic examination of specimen. Tumor stage was determined according to the 2009 UICC TNM (International Union Against Cancer, Tumor Node Metastasis) classification system [30]. Tumor differentiation was assessed according to Edmonson and Steiner grading system. The severity of the inflammation at the interface between portal tracts and the parenchyma was assessed on the H\&E stained section and graded according to Knodell et al. [31]. Fibrosis was assessed separately, as suggested by Desmet et al. [32]. The specimens were divided into four groups according to the HAI score for necroinflammation grade. The first group included biopsies with HAI 0-4 (absent activity), the second group biopsies with HAI 5-8 (mild activity), the third group biopsies with HAI 9-12 (moderate activity) and the last 
group biopsies with HAI 13-18 (severe activity). The specimens were also divided into three groups according to the degree of fibrosis, which was staged with scores ranging from 1 to 3 , corresponding to: absence or mild fibrosis (stage 1), moderate or severe (bridging) fibrosis (stage 2) and cirrhosis (stage 3).

\section{Follow-up and detection of recurrence}

All patients were followed regularly every 2-3 months after surgery until study closure in July 2010 with serum AFP/CA19-9 and abdominal ultrasonography. Progressive elevation of serum AFP/CA19-9 levels and/or ultrasonographic detection of a new hepatic lesion prompted hospitalization for confirmation of diagnosis and appropriate management, including repeat resection, radiofrequency ablation (RFA), transcatheter arterial chemoembolization (TACE) or supportive therapy. Recurrence was confirmed by contrast-enhanced imaging studies according to standard guidelines for HCC [33]. Overall survival (OS) was defined as the interval between the dates of surgery and death while disease-free survival (DFS) was defined as the interval between the dates of surgery and recurrence. If recurrence was not diagnosed, patients were censored on the date of death or the last follow-up. Clinical follow-up was not disclosed to laboratory personnel until statistical analysis.

\section{Tissue microarray (TMA) construction}

Tissue microarray (TMA) construction was described in previous reports [34]. Briefly, we constructed the tissue microarray, containing of 120 pairs of intratumoral and peritumoral liver specimens from the enrolled HCC patients. TMA slides with 120 pairs of intratumoral and matched peritumoral samples were constructed. In brief, all archival formalin-fixed and paraffin-embedded specimens used in this study were freshly sectioned and stained with haematoxylin and eosin $(\mathrm{H} \& \mathrm{E})$. The $\mathrm{H}$ \& E-stained sections were carefully reviewed by two independent pathologists without knowledge of the patients' clinical characteristics and outcomes, and the representative regions of the intratumoral and peritumoral liver tissues were defined for microarray, and the peritumoral tissues at the distance $(15 \mathrm{~mm})$ from the tumor margin were collected. Using a tissue arraying instrument (Beecher Instruments, Sliver Spring, MD), each tissue core with a diameter of $1.5 \mathrm{~mm}$ was punched from the marked areas of intratumoral and peritumoral tissues and re-embedded. TMAs containing the tissue cores were then cut into five-micrometre sections for IHC staining.

\section{Immunohistochemical staining}

Serial five-micrometre thick sections of tissue array blocks were examined immunohistochemically using a standard two-step method. Sections were de-paraffinized and rehydrated, and endogenous peroxidase was quenched with $3 \%$ peroxid $(20 \mathrm{~min})$. After antigen retrieval in $10 \mathrm{mM}$ sodium citrate buffer ( $\mathrm{pH}$ 6.0) or Ethylene Diamine Tetraacetic Acid (EDTA,1 mmol/L, PH 8.0) for $20 \mathrm{~min}$ at $95^{\circ} \mathrm{C}$, the sections then were treated with $2 \%$ normal goat serum and incubated with primary antibodies overnight at $4^{\circ} \mathrm{C}$. After washing with phosphatebuffered saline, sections were incubated with Two stept anti-rabbit or anti-mouse reagent (HRP) (Antibody, Diagnostica Inc, NY) at $37^{\circ} \mathrm{C}$ for an hour. 3,3'-Diaminobenzidine tetrahydrochloride (DAB) was used as the suitable substrate-chromogen and Mayer's hematoxylin counterstain was applied. Negative controls were treated identically but with the primary antibody omitted. Information on antibodies used and antigen-retrieval conditions are summarized in Table 5.

\section{Histopathologic and immunohistochemical evaluation}

All slides of positive HPC markers (EpCAM, OV6, C-kit and CD133) staining were observed and photographed with an Olympus microscope (IX-70 OLYMPUS, Japan). Three independent investigators examined the TMA slides without related clinical information. Under 200x magnification, images of positive representative fields were captured. The density of immunostaining was measured using Image-Pro Plus Version 6.2 software (Media Cybernetics Inc., Bethesda, MD), described previously as an established method [4]. The integrated optical density (IOD) in each image was measured, and the density of

\section{Table 5 List of antibodies used}

\begin{tabular}{|c|c|c|c|}
\hline Antibody & Source & Dilution & Antigen retrieval \\
\hline CK7 & Mouse monoclonal; Dako, Glostrup, Denmark & $1: 50$ & Citrate buffer, $\mathrm{pH} 6.0$ \\
\hline EpCAM & Mouse monoclonal; Dako, Glostrup, Denmark & $1: 200$ & Citrate buffer, pH 6.0 \\
\hline CD133 & Rabbit monoclonal; Cell Signaling Technology, Danvers, MA & $1: 100$ & Citrate buffer, pH 6.0 \\
\hline CD117 (c-kit) & Rabbit polyclonal; Dako, Glostrup, Denmark & $1: 400$ & EDTA buffer, PH 8.0 \\
\hline OV6 & Mouse monoclonal; R \& D Systems, Emeryville, CA & $1: 40$ & EDTA buffer, PH 8.0 \\
\hline PCNA & Mouse monoclonal; Cell Signaling Technology, Danvers, MA & 1:4000 & Citrate buffer, pH 6.0 \\
\hline
\end{tabular}

CK7 cytokeratin 7, EpCAM epithelial cell adhesion molecule , CD133 cluster of differentiation (CD)133, CD117 (c-kit) mast/stem cell growth factor receptor, OV6 oval cell marker, PCNA proliferating cell nuclear antigen. 
HPC markers was calculated as IOD/total area of each image. For calculating HPC markers (e.g. EpCAM, OV6, CD133 and c-kit) density, the cutoff for the definition of subgroups was the median IOD to separate high HPC markers' expression (IOD $>$ median) from low HPC markers' expression (IOD $\leq$ median) in microarray tissue samples.

\section{Evaluation of K7-DR and PI-DR}

For quantification of the total area of ductular reaction (DR), non-overlapping fields of the biopsy specimen were photographed at $100 \times$ magnification after immunohistochemical staining for CK7. The extent of CK7immunoreactive ductular reaction was semiquantitatively assessed and graded with some modification in a manner analogous to the grading of interface hepatitis in the scoring system of Ishak et al. [31]: In addition, proliferation rate in DR was evaluated by calculating the proliferating cell nuclear antigen(PCNA) labeling index as described in our previous reports [21]. Specifically, $3400 \times$ highpowered fields within each section were randomly chosen and captured. The same fields were captured in sequential serial sections stained with K7 for quantification of the number of reactive ductular cells (RDCs) in reactive ductules [35]. The proliferation index of DR (PI-DR) was calculated as ratio between the number of PCNA immunoreactive nuclei and the total number of RDCs.

\section{Statistical analysis}

Statistical analysis was performed using with SPSS 20.0 for Windows (SPSS Inc., Chicago, IL); Differences between categorical variables were assessed by the chi-square test or Fisher's exact test, when necessary. Pearson's correlation coefficient was used to determine correlations between continuous normally distributed variables. The degree of association between nonparametric or ordinal variables was assessed by using Spearman nonparametric correlation. Kaplan-Meier analysis was used to determine the survival. Log-rank test was used to compare patients' survival between subgroups; Significant variables from the univariable analysis were entered in the multivariable analysis, which was performed using the Cox-proportional hazards model with forward stepwise selection. $\mathrm{P}<0.05$ was considered statistically significant.

\section{Abbreviations}

HCC: Hepatocellular carcinoma; HPCs: Hepatic progenitor cells; DR: Ductular reaction; PI-DR: Proliferative index of ductular reaction; EpCAM: Epithelial cell adhesion molecule; CD133: Cluster of differentiation (CD)133; DFS: Disease-free survival; OS: Overall survival; PCNA: Proliferating cell nuclear antigen.

\section{Competing interests}

The authors declare that they have no competing interests.

\section{Authors' contributions}

FY: Conception and design, data analysis and interpretation, manuscript writing. YYJ: Conception and design, collection and/or assembly of data. SWG: Collection and/or assembly of data, data analysis and interpretation. GFY and QMF were responsible for data acquisition. FFQ, LG and YY were responsible for data analysis; DW, YM and FHY: Data analysis and interpretation. LXW: Conception and design, financial support, data analysis and interpretation, final approval of manuscript. All authors read and approved the final manuscript.

\section{Acknowledgments}

We thank our laboratory members for guiding the experiment and critical reading of the manuscript. This work was supported by a grant from Key Basic Research Project of China (2011CB966200, 2010CB945600,

2012CBA01303, 2011CB965100); Key project of National Natural Science Foundation of China (81030041); National Natural Science Foundation of China $(31171321,81372312,81101622,81201584)$; Special Funds for National key Sci-Tech Special Project of China (2012ZX10002-016, 2012ZX10002011-011); Shanghai Science and Technology Committee (10ZR1439600, 11ZR1449500, 12431900802, 12ZR1454200, 11 nm0504700, 09QA1407200); Shanghai Municipal Health Bureau ( XYQ2011044, 20114004); Science Fund for Creative Research Groups, NSFC, China ( 81221061).

\section{Author details}

${ }^{1}$ Tumor Immunology and Gene Therapy Center, Eastern Hepatobiliary Surgery Hospital, The Second Military Medical University, Shanghai, China. ${ }^{2}$ Department of Hepatic Surgery, Eastern Hepatobiliary Surgery Hospital, The Second Military Medical University, Shanghai, China. ${ }^{3}$ Department of Radiation Oncology, Eastern Hepatobiliary Surgery Hospital, the Second Military Medical University, Shanghai, China. ${ }^{4}$ Department of Gastroenterology, Eastern Hepatobiliary Surgery Hospital, the Second Military Medical University, Shanghai, China.

Received: 20 June 2014 Accepted: 13 August 2014 Published: 27 August 2014

\section{References}

1. Brechot C: Pathogenesis of hepatitis B virus-related hepatocellular carcinoma: old and new paradigms. Gastroenterology 2004, 127(5 Suppl 1):S56-S61.

2. Chemin I, Zoulim F: Hepatitis B virus induced hepatocellular carcinoma. Cancer Lett 2009, 286(1):52-59.

3. Wong GL, Chan HL, Tse YK, Chan HY, Tse CH, Lo AO, Wong WW: On-treatment alpha-fetoprotein is a specific tumor marker for hepatocellular carcinoma in patients with chronic hepatitis $B$ receiving entecavir. Hepatology 2014, 59(3):986-95. doi:10.1002/hep.26739.

4. Zhu XD, Zhang JB, Zhuang PY, Zhu HG, Zhang W, Xiong YQ, Wu WZ, Wang $L$, Tang $Z Y$, Sun HC: High expression of macrophage colony-stimulating factor in peritumoral liver tissue is associated with poor survival after curative resection of hepatocellular carcinoma. J Clin Oncol 2008, 26(16):2707-2716.

5. Roskams TA, Theise ND, Balabaud C, Bhagat G, Bhathal PS, Bioulac-Sage $P$, Brunt EM, Crawford JM, Crosby HA, Desmet V, Finegold MJ, Geller SA, Gouw AS, Hytiroglou P, Knisely AS, Kojiro M, Lefkowitch JH, Nakanuma Y, Olynyk JK, Park YN, Portmann B, Saxena R, Scheuer PJ, Strain AJ, Thung SN, Wanless IR, West AB: Nomenclature of the finer branches of the biliary tree: canals, ductules, and ductular reactions in human livers. Hepatology 2004, 39(6):1739-1745.

6. Saxena R, Theise N: Canals of Hering: recent insights and current knowledge. Semin Liver Dis 2004, 24(1):43-48.

7. Strazzabosco M, Fabris L: Neural cell adhesion molecule (NCAM) and polysialic acid in ductular reaction: The puzzle is far from completed, but the picture is becoming more clear. Hepatology 2014. doi:10.1002/hep.27291.

8. Xu M, Xie F, Qian G, Jing Y, Zhang S, Gao L, Zheng T, Wu M, Yang J, Wei L: Peritumoral ductular reaction: a poor postoperative prognostic factor for hepatocellular carcinoma. BMC Cancer 2014, 14:65.

9. Clouston AD, Powell EE, Walsh MJ, Richardson MM, Demetris AJ, Jonsson JR: Fibrosis correlates with a ductular reaction in hepatitis C: roles of impaired replication, progenitor cells and steatosis. Hepatology 2005, 41(4):809-818. 
10. Richardson MM, Jonsson JR, Powell EE, Brunt EM, Neuschwander-Tetri BA, Bhathal PS, Dixon JB, Weltman MD, Tilg H, Moschen AR, Purdie DM, Demetris AJ, Clouston AD: Progressive fibrosis in nonalcoholic steatohepatitis: association with altered regeneration and a ductular reaction. Gastroenterology 2007, 133(1):80-90.

11. Strazzabosco M, Fabris L: Development of the bile ducts: essentials for the clinical hepatologist. J Hepatol 2012, 56(5):1159-1170.

12. Gouw AS, Clouston AD, Theise ND: Ductular reactions in human liver: diversity at the interface. Hepatology 2011, 54(5):1853-1863.

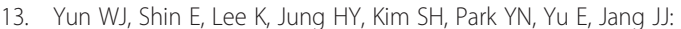
Clinicopathologic implication of hepatic progenitor cell marker expression in hepatoblastoma. Pathol Res Pract 2013, 209(9):568-573.

14. Zhang F, Chen XP, Zhang W, Dong HH, Xiang S, Zhang WG, Zhang BX: Combined hepatocellular cholangiocarcinoma originating from hepatic progenitor cells: immunohistochemical and double-fluorescence immunostaining evidence. Histopathology 2008, 52(2):224-232.

15. Yamashita $T$, Ji J, Budhu A, Forgues $M$, Yang W, Wang HY, Jia $H$, Ye $Q$, Qin LX, Wauthier E, Reid LM, Minato H, Honda M, Kaneko S, Tang ZY, Wang XW: EpCAM-positive hepatocellular carcinoma cells are tumor-initiating cells with stem/progenitor cell features. Gastroenterology 2009, 136(3):1012-1024

16. He YF, Liu YK, Lu HJ, Chen J, Yang PY: Comparative proteomic analysis of primary mouse liver c-Kit-(CD45/TER119)- stem/progenitor cells. J Cell Biochem 2007, 102(4):936-946.

17. Yamashita T, Forgues $M$, Wang W, Kim JW, Ye Q, Jia H, Budhu A, Zanetti KA, Chen Y, Qin LX, Tang ZY, Wang XW: EpCAM and alpha-fetoprotein expression defines novel prognostic subtypes of hepatocellular carcinoma. Cancer Res 2008, 68(5):1451-1461.

18. Yang XR, Xu Y, Yu B, Zhou J, Qiu SJ, Shi GM, Zhang BH, Wu WZ, Shi YH, Wu $B$, Yang GH, Ji Y, Fan J: High expression levels of putative hepatic stem/ progenitor cell biomarkers related to tumour angiogenesis and poor prognosis of hepatocellular carcinoma. Gut 2010, 59(7):953-962.

19. Chiba T, Zheng YW, Kita K, Yokosuka O, Saisho H, Onodera M, Miyoshi H, Nakano M, Zen Y, Nakanuma Y, Nakauchi H, Iwama A, Taniguchi H: Enhanced self-renewal capability in hepatic stem/progenitor cells drives cancer initiation. Gastroenterology 2007, 133(3):937-950.

20. Nijjar SS, Wallace L, Crosby HA, Hubscher SG, Strain AJ: Altered Notch ligand expression in human liver disease: further evidence for a role of the Notch signaling pathway in hepatic neovascularization and biliary ductular defects. Am J Pathol 2002, 160(5):1695-1703.

21. Cai X, Zhai J, Kaplan DE, Zhang Y, Zhou L, Chen X, Qian G, Zhao Q, Li Y, Gao L, Cong W, Zhu M, Yan Z, Shi L, Wu D, Wei L, Shen F, Wu M: Background progenitor activation is associated with recurrence after hepatectomy of combined hepatocellular-cholangiocarcinoma. Hepatology 2012, 56(5):1804-1816.

22. Lennerz JK, Chapman WC, Brunt EM: Keratin 19 epithelial patterns in cirrhotic stroma parallel hepatocarcinogenesis. Am J Pathol 2011, 179(2):1015-1029.

23. Vandersteenhoven AM, Burchette J, Michalopoulos G: Characterization of ductular hepatocytes in end-stage cirrhosis. Arch Pathol Lab Med 1990, 114(4):403-406.

24. Thung SN: The development of proliferating ductular structures in liver disease. An immunohistochemical study. Arch Pathol Lab Med 1990, 114(4):407-411.

25. Sancho-Bru P, Altamirano J, Rodrigo-Torres D, Coll M, Millan C, Jose Lozano J, Miquel R, Arroyo V, Caballeria J, Gines P, Bataller R: Liver progenitor cell markers correlate with liver damage and predict short-term mortality in patients with alcoholic hepatitis. Hepatology 2012, 55(6):1931-1941.

26. Delladetsima J, Alexandrou P, Giaslakiotis K, Psichogiou M, Hatzis G, Sypsa V, Tiniakos D: Hepatic progenitor cells in chronic hepatitis C: a phenomenon of older age and advanced liver disease. Virchows Arch 2010, 457(4):457-466.

27. Hoshida Y, Villanueva A, Kobayashi M, Peix J, Chiang DY, Camargo A, Gupta S, Moore J, Wrobel MJ, Lerner J, Reich M, Chan JA, Glickman JN, Ikeda K, Hashimoto M, Watanabe G, Daidone MG, Roayaie S, Schwartz M, Thung S, Salvesen HB, Gabriel S, Mazzaferro V, Bruix J, Friedman SL, Kumada H, Llovet JM, Golub TR: Gene expression in fixed tissues and outcome in hepatocellular carcinoma. N Engl J Med 2008, 359(19):1995-2004.

28. Bae JS, Noh SJ, Jang KY, Park HS, Chung MJ, Park CK, Moon WS: Expression and role of epithelial cell adhesion molecule in dysplastic nodule and hepatocellular carcinoma. Int J Oncol 2012, 41(6):2150-2158.
29. Yoon SM, Gerasimidou D, Kuwahara R, Hytiroglou P, Yoo JE, Park YN, Theise ND: Epithelial cell adhesion molecule (EpCAM) marks hepatocytes newly derived from stem/progenitor cells in humans. Hepatology 2011, 53(3):964-973.

30. Sobin LH, Gospodarowicz MK, Wittekind C: International Union against Cancer. TNM classification of malignant tumours. 7th edition. Chichester, UK, Hoboken, NJ: Wiley-Blackwell; 2010:2110-2114.

31. Ishak K, Baptista A, Bianchi L, Callea F, De Groote J, Gudat F, Denk H, Desmet V, Korb G, MacSween RN, Phillips MJ, Portmann BG, Paulsen H, Scheuer PJ, Schmid M, Thaler H: Histological grading and staging of chronic hepatitis. J Hepatol 1995, 22(6):696-699.

32. Scheuer PJ: Classification of chronic viral hepatitis: a need for reassessment. J Hepatol 1991, 13(3):372-374.

33. Bruix J, Sherman M: Practice Guidelines Committee AAftSoLD: Management of hepatocellular carcinoma. Hepatology 2005, 42(5):1208-1236.

34. Au NH, Cheang M, Huntsman DG, Yorida E, Coldman A, Elliott WM, Bebb G, Flint J, English J, Gilks CB, Grimes HL: Evaluation of immunohistochemical markers in non-small cell lung cancer by unsupervised hierarchical clustering analysis: a tissue microarray study of 284 cases and 18 markers. J Pathol 2004, 204(1):101-109.

35. Falkowski $O$, An HJ, lanus IA, Chiriboga L, Yee H, West AB, Theise ND: Regeneration of hepatocyte 'buds' in cirrhosis from intrabiliary stem cells. J Hepatol 2003, 39(3):357-364.

doi:10.1186/2045-3701-4-50

Cite this article as: Ye et al.: Proliferative ductular reactions correlate with hepatic progenitor cell and predict recurrence in HCC patients after curative resection. Cell \& Bioscience 2014 4:50.

\section{Submit your next manuscript to BioMed Central and take full advantage of:}

- Convenient online submission

- Thorough peer review

- No space constraints or color figure charges

- Immediate publication on acceptance

- Inclusion in PubMed, CAS, Scopus and Google Scholar

- Research which is freely available for redistribution

Submit your manuscript at www.biomedcentral.com/submit
C) Biomed Central 